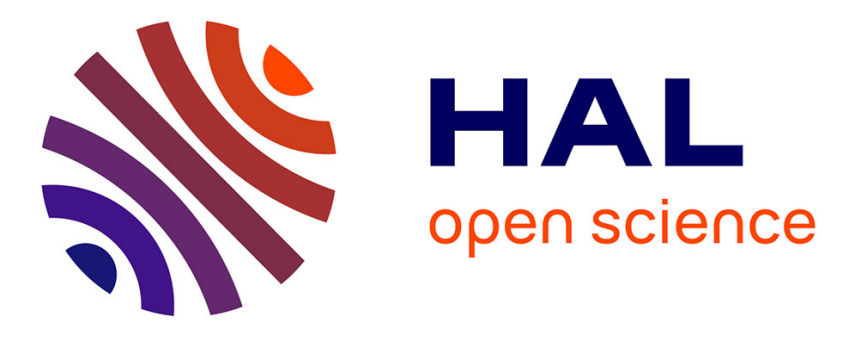

\title{
From theory to bricolage: indiscipline and the exemplary gestures of interpretation \\ Yves Citton
}

\section{To cite this version:}

Yves Citton. From theory to bricolage: indiscipline and the exemplary gestures of interpretation. International Social Science Journal, 2012, States of Theory: Contemporary Schools of Thought and Institutions of Knowledge, 63 (207-208), pp.53-66. 10.1111/issj.12013 . hal-01373204

\section{HAL Id: hal-01373204 https://hal.science/hal-01373204}

Submitted on 28 Sep 2016

HAL is a multi-disciplinary open access archive for the deposit and dissemination of scientific research documents, whether they are published or not. The documents may come from teaching and research institutions in France or abroad, or from public or private research centers.
L'archive ouverte pluridisciplinaire HAL, est destinée au dépôt et à la diffusion de documents scientifiques de niveau recherche, publiés ou non, émanant des établissements d'enseignement et de recherche français ou étrangers, des laboratoires publics ou privés. 


\section{Yves Citton}

\section{From Theory to Bricolage: Indiscipline and the Exemplary Gestures of Interpretation}

\section{ABSTRACT}

This article suggests that our supposedly "post-theoretical" age is more than ever in need of the intellectual gestures which characterized theory in its various guises. After a brief historical schematization of the recent evolutions of theory, it distinguishes four dimensions of intellection (accounting, modeling, storytelling, speculating), which are constantly weaved together whenever we attempt to make sense of our world. It then shows that these four dimensions are all included in the activity of interpretation, which deserves to appear as a continuation of theory by other means. In dialogue with Wlad Godzich, Steven Knapp and Walter Ben Michaels, Daniele Giglioli or Claude Lévi-Strauss, it re-describes interpretation as a form of indiscipline closer to the bricolage of "the savage mind" than to the unrealistic idealization of modern "Science". It concludes, however, by rejecting such dichotomies and by calling for "theoricolage" as an indisciplinary and cheerful mix of theory and bricolage.

\section{BiOgRAPHICAL Note}

Yves CitTon is professor of French Literature of the 18th Century at the Universite de Grenoble-3 and a member of the UMR LIRE (CNRS 5611). He taught for 12 years in the department of French and Italian of the University of Pittsburgh, PA, and has been Invited Professor at New York University, Harvard and Sciences-Po Paris. He recently published Gestes d'humanités. Anthropologie sauvage de nos expériences esthétiques (Paris: Armand Colin, 2012), Renverser l'insoutenable (Paris: Seuil, 2012), Zazirocratie. Très curieuse introduction à la biopolitique et à la critique de la croissance (Paris, Éditions Amsterdam, 2011), L'Avenir des Humanités. Économie de la connaissance ou cultures de l'interprétation? (Paris, Éditions de la Découverte, 2010), Mythocratie. Storytelling et imaginaire de gauche (Paris, Éditions Amsterdam, 2010), Lire, interpréter, actualiser. Pourquoi les études littéraires? (Paris, Éditions Amsterdam, 2007) and L'Envers de la liberté. L'invention d'un imaginaire spinoziste dans la France des Lumières (Paris, Éditions Amsterdam, 2006, which won the Prix Rhône-Alpes du Livre 2007). He co-edited, with Frédéric Lordon, Spinoza et les sciences sociales. De la puissance de la multitude à l'économie des affects (Paris, Éditions Amsterdam, 2008) and, with Martial Poirson, Les Frontières littéraires de l'économie (Paris, Éditions Desjonquères, 2008). He co-directs the journal Multitudes and writes regular chronicles in the Revue des Livres. 
As a French speaker working for a dozen years in US academia around the 1990s, I always found it uncanny (and slightly worrying) to hear my native colleagues speak of "Theory" in an absolute sense. Even when the "theorists" for whom I had the highest admiration defined "theory as a practice of dissidence and of echoing the cry" (Godzich 1994, 31), I felt uneasy and puzzled by the very possibility to refer to "theory" as such, i.e., without specifying who's or what theory one had in mind. As far as I was concerned, there were theories (in the plural), contradicting or completing each other, calling for each one of us to choose, reject, discuss, denounce, correct, refine, pursue, deepen them.

Much to my dismay, I realized that the MA students in my 2011 course in Literary Theory at the University of Grenoble also referred to "la théorie" in the singular rather than in the plural. When I asked them why they registered in the class, their response was straightforward: because it was compulsory. After twelve weeks of (enforced) weekly meetings, while some of them acknowledged having enjoyed and benefited from the class, they remained unanimous in suggesting a change of title: the reference to "la théorie" had no appeal whatsoever, working rather as a strong repellent. They did not see what was to be gained in theory: they wanted to read literary texts, discuss them, their form, their agency, their relevance, their impact - but theory was an obstacle rather than a help to do so.

My French colleagues were typically unaffected by such feedback. Students, after all, don't know what's good for them: that's why they learn, and that's why we teach. They'll realize later how important theory (or literary history, or methodology) is, when they grow up. As a firm believer in Jacques Rancière's presupposition of the equality of intelligence, I find it harder to disqualify my students' perceptions and claims. I'd rather hear them as a symptom of a certain obsolescence of "theory". More precisely, I suspect that their rejection of "la théorie" deeply resonates with my own uneasiness towards "theory". When theory becomes absolutized and essentialized, as symptomatized by the use of the singular to refer to it, time may have come to move on and rid ourselves of a label now lacking in traction.

In this article, however, I will not join the large chorus of those who announce the "death of theory" - whether to bemoan or to celebrate it - and see us enter a new "posttheoretical" era (see for instance McMillan 1999; Butler 2000; Eagleton 2003; Callus 2004; Zublena 2011). Instead, I will attempt briefly to sketch an evolution of theory, which looks simultaneously and somewhat contradictorily like an involution (turning back onto itself) and like an unfolding (opening up to spread into every domain of action). It would indeed be a good thing if theory (in the singular) was nowhere to be found-if only it meant that it is now diffusely present and active everywhere.

It may be a good starting point to appropriate for our topic what Frank Zappa famously said about jazz: Theory is not dead, it just smells funny. How did it come to smell that way? What exactly does it now smell like? What is to be done with that smell? These are the questions I will address in the following pages.

\section{From Pre-History to Post-Theory}

The evolution of the references made to "theory", over the past 50 years, can be roughly summarized in three main phases. Around the $1950 \mathrm{~s}$, during what I would call the prehistoric age of theory, there were many competing theories, attached to many different fields, with several candidates struggling for prominence within each discipline. These theories in the plural, however, were all but pluralistic: each of them claimed to provide the only true and valid definition and framing of its object. There were many, but each was animated with an exclusivist urge. The most common rivalries opposed Marxist approaches to bourgeois points of view, holism to individualism, deductive modeling to empiricist induction. In spite of their constant struggles, all the competitors shared a number of common features: they claimed to be scientific, systematic, objective, they throve on binary oppositions and on the working out 
of contradictions, they saw their competition as geared towards a common progress of human knowledge. In other words, to borrow from Bruno Latour (1991, 168 \& 2012, 520), they believed they were "modern".

This pre-historic age is far from over: a lot of scientists still live in it (more or less happily), mapping the advancement of their discipline through Popperian refutations and Kuhnian paradigm shifts. As a matter of fact, we are all pre-historic theorists insofar as our work is structured by disciplined forms of research. Any discipline rests on a certain systematicity, on efforts towards objectivity, towards the avoidance of self-contradictions, etc. We may very well "never have been modern", but our disciplinary endeavors were- and still are.

"Theory" entered into its historical age as an attempt to break with this modernity. The most suggestive description of this attempt, and of its puzzling implications, was provided by Wlad Godzich, who played a central role in the development of theory in the USA as coeditor of the series "Theory and History of Literature" at the University of Minnesota Press. As François Cusset analyzed it in his book French Theory, this historical age was dominated by references to "Derrida, Foucault, Lyotard, Deleuze, and the Yale School" (Godzich, 1994, 19). Its "fundamental concern" was "difference"-which, on the face of it, makes it all the more puzzling that it consistently referred to itself in the singular (theory, difference) rather than in the plural. In using "difference" to denounce and undermine "the project of an exhaustive ordering of things and practices" pushed forward by the (Hegelian) ambition of modern Science (Godzich 1994,24), French theory was led to develop a very peculiar sensibility and endeavor of its own, which Wlad Godzich cleverly articulates in terms of "dissidence" and of "echoing of a cry":

Difference-sensitive theory has recognized and thematized something that had escaped earlier thought: the cry. It is a philosophy of the cry, a cry constituted by difference in all of its avatars. [...] A dissident is someone who denounces, and bears witness to, the abyss that separates reality from its official version. A dissident's stance draws attention to and inhabits this difference, letting it progressively inscribe itself in the dissident's very body. [...] Theory as a practice of dissidence and of echoing the cry thus situates itself at the intersection of the cry and of the System, and its practice consists in inventing gestures that are, at one and the same time, dedicated to the cry and a demand for an accounting from the System. This uncomfortable position is that of theory marginalizing itself, for such a practice of theory could not seek to occupy the center. (Godzich, 1994, 26 \& 31)

Although "difference" has many "avatars", theory_in its historical age - searched and nurtured it as a vector for the repeated self-same gesture of pointing to "the abyss that separates reality from its official version". Theory "marginalized itself" from the theories elaborated in its pre-historical age, as soon as they became accepted by "the System" as a part of its "official version" of reality.

The "cry" expresses that which resists against being reduced to the official version of reality promoted by "the System": native Indians displaced from their ancestral lifeworld by the invasion of modernity, along with its science, technology and mining companies; gay and lesbians whose "queer" behavior blurs the dichotomies between male and female; steelworkers who hang on to their industrial jobs against the promise of immaterial production; poets whose voice has no place left in a communicative universe dominated by the circulation of commodities and information. Theory took it on itself to hear and echo such cries: its form of dissidence consisted in becoming a porte-parole, a voice for the voiceless, elevating the cry to the status of a "demand for an accounting from the System". 
In this second phase, theory set itself up for what could hardly be anything else than a history of necessary failure and repeated disappointments. At least three factors can explain the necessarily doomed nature of this historical phase.

First, a dissident only pursues her dissidence as long as she maintains a very fragile balance between a capacity to be heard (without which she simply does not exist as a dissident) and a capacity not to be heard (since she ceases being a dissident when she becomes accounted for by the System). This "uncomfortable position" explains why theory and difference were led to conceive of themselves in the singular: as soon as this particular cry, this particular form of difference and dissidence can be named, identified, distinguished, categorized, they are absorbed by the System, accounted for within the projected "exhaustive ordering of things and practices". Marginalizing oneself is therefore bound to be an endlessly vanishing task, since one exists (in the margin) only as long as one does not exist (for the System, from which one can never completely break apart).

Second, as Wlad Godzich himself clearly identified at the end of his essay, this "uncomfortable position" raised not only ontological or epistemological difficulties, but also socio-professional ones: "this is the gravest menace to theory today: its professionalized simulacrum, well ensconced in the system of knowledge, usurping the voice of the Other while silencing it and the practice of resistance that is genuine theory" (Godzich 1994, 33). Theorists, like everyone else, need bread and incomes: they look for (academic) jobs and, if lucky, get to teach the current "system of knowledge"; they are sometimes led to run departments and, as representatives of the System, they have to account for other people's actions, caught in the process of writing the official version of reality. All of this makes it difficult to be (and remain) a dissident.

Third, difference and dissidence are caught in the same self-destructive trapping on the methodological level as on the socio-professional level. While each of the many avatars of the cry would require its own peculiar treatment, "deconstruction" soon became an allencompassing method of its own, a rigid discipline geared towards debunking all disciplines. The demise of theory-as-difference was already inscribed in the (in)famous article written by Steven Knapp and Walter Benn Michaels as early as 1982 under the provocative title "Against Theory":

By "theory" we mean a special project in literary criticism: the attempt to govern interpretations of particular texts by appealing to an account of interpretation in general. [... Theory] is the name for all the ways people have tried to stand outside practice in order to govern practice from without. Our thesis has been that no one can reach a position outside practice, that theorists should stop trying, and that the theoretical enterprise should therefore come to an end. (Knapp and Benn Michaels 1982, 723 \& 742)

Our supposedly "post-theoretical" age was already written in the very dynamics of theory, whose historical phase was bound to be a repetitive exercise in self-destruction. Yes, theory, in its deconstructionist guise, became "an account of interpretation in general", imposed from above by a System of departmental chairs and committees in order to govern interpretations of particular texts, along the mainstream doxa and dogma of endless marginalization. Yes, it became a discipline, entering the same competition for exclusive domination which characterized the pre-historical claims of the (plural though anti-pluralist) theories. The history of this phase of theory has clearly run its course for at least a decade, and it is therefore accurate to describe our age as "post-theoretical".

Yet, since the stabilization of theory in "its professionalized simulacrum, well ensconced in the system of knowledge" was an "usurpation" of its true dissident dynamics, we could as well claim that theory has a better chance to realize its promise now that it is again marginalized from most of the institutions it briefly conquered (or usurped). Apart from 
the paradoxical fact that French theory never conquered any real power in French institutions, my students' scorn for theory in Grenoble bears witness to its current (re)marginalization. We are indeed in a "post-theory" age when we compare our current discussions with this observation made by Wlad Godzich two decades ago: "in spite of a constant barrage of denunciations of its ephemeral faddishness and predictions of its imminent demise, theory has managed to occupy an inordinate amount of our attention and has imposed itself as the defining characteristic of an entire generation of scholarship" (Godzich, 1994, 15).

My students' generation does not even bother to denounce the faddishness, the abstraction or the jargon of theoretical pyrotechnics: they just don't care. They only take theory courses because well-ensconced professors and chairs have made them compulsory in the current system of knowledge acquisition. It would be fair to reply that incoming MA students in French or CompLit in the 1980s at Yale also took theory as a form of bad-tasting medicine, because chairs had made it (officially or implicitly) compulsory. Theory did nevertheless manage "to occupy an inordinate amount of our attention" in these days, which certainly is no longer the case. No one pays attention anymore. My student take it as an oldfashioned ritual, as a medication they know to be a mere placebo.

Does living in a "post-theory" age mean, as Steven Knapp and Walter Ben Michaels prophetically claimed, that we should "stop trying to stand outside practice in order to govern practice from the outside", because "no-one can reach a position outside practice", calling for "the theoretical practice to come to an end"? I certainly do not believe so. The rest of my reflection will suggest that the theoretical urge-in its pre-historical "modern" form of progressive systematicity and in its historical form of echoing the cry-is in a better position than ever to accomplish its enlightening practice of dissidence, now that the dominance of "theory" is a thing of the past. My claim will be that indisciplinary interpretation is now our chance to pursue theory through other (better) means.

\section{Four Dimensions of Intellection}

Theory's self-demise was inscribed in its inconsistent relation to pluralism, reducing the multiple ways of knowing, of crying and of resisting to the mere "avatars" of a one same selfperpetuating principle of "Difference". The indisciplinary approach I am advocating here attempts to reconcile the (modern) effort to elaborate systematic accounts of our lifeworld with the (postmodern) intuition that dissidence carries both the dynamics of progress and the antidote to the excesses committed in the name of progress.

If important knowledge mostly comes from the margins, we need to put ourselves in position to integrate difference without neutralizing it, which is why pluralism is our most fundamental requirement. A truly indisciplinary approach should give pluralism a radical form. In reaction against the exclusive claims which animated theories of the pre-historical age - each competing to assert its own truth by attacking the assertions made by its rivalswe should go as far as pre-supposing that all forms of knowledge have some truth in them, and, conversely, that no form of knowledge can pretend to be valid thru and thru. We need pluralism because our collective intelligence is necessarily situated in between the various forms of knowledge currently at our disposal; we need this pluralism to be as large, inclusive, flexible, tolerant as possible because even the most wacky theory has something to contribute to it.

Against the inherent and necessary tendency of any discipline to isolate one approach and one layer of reality upon which it concentrates its attention, we need to conceive of any intellectual endeavor as a variable mix of at least four different types of activity. I will briefly sketch these four types, which can be seen as four dimensions of intellection.

1. The first dimension consists in accounting, i.e., in observing, categorizing, numbering, quantifying and describing certain segments of reality isolated within the constant 
flow of stimuli that reach our sensory apparatus during our waking hours. At the most mundane and banal level, we perform this activity at every second of the day, in order to be aware of our environment and to react to its evolution in the manner most appropriate to our functional needs. But it is the same type of activity which is performed, along much more complex mediations, when a physicist sends subatomic particles to crash into each other within a supercollider, when a sociologist painfully gathers data about standards of living and educational levels, when a trader attempts to get a clear idea of a company's potential profitability, or when a poet twists our common language in order to devise a more accurate way to account for our subjective experiences.

The task of accounting requires us to select certain data as relevant and to quantify their iterations. It looks flatly "empiricist" (observing what's there), and therefore "pre-theoretical", only if we forget that relevance results from a very complex weaving of sensitivities, interests, attachments, meanings and interpretations. We only pay attention to data that have been selected because of their possible impact on certain practices that matter to us. Facts and data never impose themselves upon us, they are "matters of fact" only because they have been previously experienced as "matters of concern".

Apart from its analytical aspect of distinguishing and numbering segments of reality, the task of accounting consists mostly in the art of aggregating heterogeneous data. It is an art of translation, of devising common measures able to draw together, compare, align, equate originally incommensurable things (Akrich et al. 2006, 11). Its specific challenge comes from the difficulty to find the proper measuring stick telling us when different things can be counted as one, as many or as equivalent.

2. Far from being reducible to mere observation, accounting is therefore intimately tied to a second type of activity, for which we can propose the generic name of modeling. While accounting approaches reality in synchronic terms of time-slices (what is to be counted at a given moment within a given field of observation?), modeling rests on an effort to predict diachronic transformations referred to causal explanations. These two activities are developed in constant conjunction: I will pay attention to something, I will consider it as relevant, and I will try to isolate it in the flow of sensory stimuli, only on the basis of a certain "model"- - or of a "scheme", to follow the powerful insights and terminology developed in Philippe Descola 2005. This is the foundation of the principle of relevance (or pertinence): I isolate a segment of reality only because I was led to believe it may play a causal role in processes that are of interest to my practices.

Modeling rests on past experiences in order to project expectations in the future, on the basis of hypotheses of causal relations. It roughly corresponds to the scientific theories of the pre-historical age, without perpetuating the ideological divide between the supposed certainty of modern Science and the pragmatic trials-and-errors of savage "bricolage" (Levi Strauss 1966, more on this later). Both accounting and modeling presuppose a view from above, illustrated by the cartographic gaze, the physicist's system of equations and the architect's miniature model. This view from above has long been thought to be central to the definition of theory, referring back to its etymological origin of theôria ( $\theta \varepsilon \omega \rho i ́ \alpha$, "contemplation", "observation"): to "theorize" is to look at a part of reality from a certain distance and with a certain pretense to superiority. While this aspect tended explicitly to be denied by differencesensitive theory, it nevertheless animated (and haunted) its very practice: its much criticized "jargon" resulted from an attempt to take distance towards the cry, in order to map its conditions of emergence, its meaning, its implications, and its possible future agency.

3 . The third type of activity, storytelling, may appear as a mere variation on modeling. It too attempts to follow the temporal unfolding of transformations occurring in our, or in someone else's, living experience; it too leads us to project causal explanations (propter hoc) on chronological successions (post hoc). A story is indeed a "model", as Paul Ricoeur has 
convincingly shown in Time and Narrative, and as economists still suggest in their everyday language, when they say that "they have a story" (i.e., a theory) to explain a certain set of empirical observations.

We should however follow anthropologist Tim Ingold when he characterizes storytelling by a certain type of movement, which he relates to "wayfaring" as illustrated by the hunters and gatherers' walks in the forests. In contrast to our modern ways of life which favor both "transport" (a movement across, going from point A to point B in the most direct and speedy fashion) and "survey" (a movement up, in a tower, a helicopter, an airplane or a satellite), hunters and gatherers walk along unpredictable paths, turning right or veering left in order to follow one prey's track or to get nearer to another prey's cry. While we can sleep or read a book during transport in a train, while the surveying gaze provides us with a deterritorialized point of view, wayfaring is defined by "the intimate bond that couples locomotion and perception" (Ingold, 2007, 78).

Such is also the type of intellectual movement generated by storytelling, which distinguishes it from the activity of modeling: even if narratives usually include an explanatory dimension, their characteristic mode of experience consists in espousing the wayfarer's point of view along her path of life. "It is in the art of storytelling, not in the power of classification, that the key to human knowledgeability-and therefore to cultureultimately resides". We need stories to draw and weave "together what classifications split apart" (Ingold 2011, 160 \& 164):

To tell a story is to relate, in narrative, the occurrences of the past, bringing them to life in the vivid present of listeners as if they were going on here and now. Here, the meaning of the "relation" has to be understood quite literally, not as a connection between predetermined entities, but as the retracing of a path through the terrain of lived experience. [...] To tell, in short, is not to represent the world, but to trace a path through it that others can follow. (Ingold, 2011, 161)

This is precisely why difference-sensitive theory was so intimately linked to literature, whether in its academic location (departments of French, English, Spanish, Comparative Literature) or in the emphasis it put on the notion of "writing". Implicitly or explicitly, it tended to put accounting and modeling on the side of "the System" (with its ordering and mapping of things and practices, under the dominance of a surveying gaze), while putting itself on the side of dissidents whose emblematic figures were storytellers. A narrative provides a much more appropriate venue than a theory for "echoing the cry". It is in the wayfarer's experience that we can find the strongest potential for dissidence and resistance, since the wayfarer remains as close as possible to reality, at the field level, while the theorist always runs the risk of being disconnected from reality by the abstraction of his classifications and superior gaze.

4. My fourth dimension of intellection could also be considered as a variation or as a particular aspect of modeling, but, here too, I find it important simultaneously to stress the vicinity and the difference in nature between these various activities. Speculating not only provides possible explanations on future course of events, it also includes a strongly reflexive dimension: the speculum is first and foremost a "mirror", which allows a person to look at herself, to make sense of her own image within the surroundings in which it appears. Speculating gives theory its (self-)critical and (self-)reflexive stance, which tends to permeate the three activities previously mentioned: counting and aggregating, explaining and predicting, narrating and expressing only enter the theoretical domain insofar as they include some form of awareness of their own gestures and problems.

In addition to this reflexive stance, the speculative activity has recently been reinvested with new meaning, thanks in part to Quentin Meillassoux's surprisingly popular essay After 
Finitude. By claiming that the only necessary principle is to be found in the absolute contingency of all things and events, Meillassoux's metaphysics open up a (very abstract but nevertheless very open) space for the exploration of the possible. While the recent grouping of continental philosophers as diverse as Meillassoux, Deleuze, Guattari, Badiou, Latour or Žižek under the single umbrella of a co-called "speculative turn" remains subject to debate, the attempt to "aim at something 'beyond' the critical and linguistic turns", expressing a renewed form of "realism and materialism" animated with "a concern with the Absolute" suggests a curious emerging mix of ontological ambition and creative self-assertion (Bryant et al, 2011, 3).

What does it mean for someone to "speculate", after all, if not to look beyond the actual reality as it is given to our senses, in order better to envision another possible world? While accounting and modeling attempt to describe the given state of reality (as it stands and as it works), while storytelling can refer to the sequences of events that happened in the actual world, speculating is intrinsically linked to worldmaking, and to projecting oneself into a universe of fiction. The speculative question could be phrased as follows: how can I see myself realistically living in a different actual world?

\section{Four Modalities of Interpretation}

As it should be clear by now, the four types of activities I just listed do not attempt to be clearly and distinctly separated from each other. They constantly overlap within each effort we make in order to situate ourselves in the world. I presented them as four dimensions of intellection precisely to suggest that they always come in a (slightly different) bundle, in the same way as any physical object can be perceived in terms of length and height and depth.

My claim can thus be stated as follows: the theoretical drives-which can no longer be conceived in the singular but which must put plurality at the core of their self-definitionconstantly invent a myriad of practical modes of weaving together the four threads of activity described above as accounting, modeling, storytelling and speculating. What used to be called "a theory" in the pre-historical age, then simply "theory" under the reign of Difference, consisted in certain particular modes of tying these threads together. Some of these modes may now seem obsolete, leading some analysts and critics to claim that "Theory is dead". Others are still practiced or seem appealing enough so that we may want to experiment with them again, in which case it is just as accurate to say that "Theory is alive and well".

These four activities constitute four different modalities of what has been referred to as "interpretation", so that we could highjack von Clausewitz's famous statement describing war as the continuation of politics by other means, and conceive interpretation as the continuation of theory by other means. To clarify this claim, I will briefly refer to the special case of literary theory, which can help us understand the broader articulation between interpretation and theory.

Let's recall the opening claim made by Knapp and Benn Michael in their declaration of war "Against Theory": "By 'theory' we mean a special project in literary criticism: the attempt to govern interpretations of particular texts by appealing to an account of interpretation in general". Theory has been perceived as imperialistic, hegemonic, because of its claim to look at things from above: it pretended to provide a general "account", valid for all practical acts of reading, and it pretended to "model" the proper way to read any text, imposed from the top in the name of some superior form of intelligence. Hence my current MA students' perception that theory is abstract, overly general, cut from the reality of concrete issues, unrelated to what really counts ("practice"). In other words, theory is blamed for being (purely) "theoretical".

If we consider any act of intellection as the weaving of the four dimensions listed above, we see that accounting and modeling, as well as speculating, do indeed introduce a certain 
"view from above". We also realize, however, that the activity of accounting, in its necessary concreteness, and that the wayfaring progression of the storyteller, also included in the mix, contain potential antidotes to traditional excesses of the superior gaze.

More importantly, and much more radically, we realize that the traditional distinction and rivalry between "theory" and "practice", between the superior status of theory prescribing how to read all discourses and the practical interpretations of concrete texts rests on a deceptive opposition. There can be no accounting, modeling, storytelling or speculating "in general": we must necessarily count something given to our senses, model some specific chain of events, tell one particular story, speculate about certain possible transformations of our being. Similarly, within the literary field, all theories claiming to provide universal models accounting for the working of any possible text can be easily shown to result from the consideration of a certain specific corpus, which generated certain biases, certain sensibilities, certain negligence, certain implicit norms and certain unduly exclusions. In other words, all theories result from the attempt to generalize certain given interpretations.

Conversely, there can be no interpretation which does not rest (implicitly or explicitly) on a certain generalization, prescribing what there is to look for in a text, how to look for it and why. Over the past half-century, from Hans-Georg Gadamer to Roland Barthes, from Umberto Eco to Michel Charles, literary theory has shown how literary interpretations are permeated thru and thru with a complex interplay of welcoming a fundamentally alien message (Blanchot 1989, 277), of projecting a hallucinated meaning (Fish,1981, 394), of simultaneously describing, prescribing and performing the text (Shustermann 1984, 237), making it impossible to maintain a clear-cut opposition between construing (that which is given by the text) and constructing (that which only appears because one has made oneself attentive to its presence) (Fish, 1981, 394). The interpretive practice is precisely located at the intersection of both movements: it requires both an attentiveness to what's there (in the text) and a pre-existing model which pre-conditions our attention.

We now see more clearly where Steven Knapp and Walter Benn Michaels had it wrong when they called for theory to "come to an end". When claiming that theory "has no practical consequences, not because it can never be united with practice, but because it can never be separated from practice" (Knapp \& Benn Michaels 1982, 741), they were right to state that theory and practice cannot be fully separated, since interpretation necessarily requires accounting and modeling, observing and speculating. However, they flattened (and therefore killed) the interpretive operation by failing to account for the necessary movement back and forth - or rather up and down - which is at the core of its dynamics. Far from calling for theory to come to an end, we need it to keep trying to "reach a position outside practice"above it - because this attempt, although it necessarily produces deceptive and disappointing results, is constitutive of the interpretive gesture, and of intellection at large.

Accounting, modeling, storytelling, speculating are all various forms of interpretation: they result from a certain sensitivity to what's there, as this sensitivity has been structured by the principle of relevance, which emerges from the interface between functional needs, practical interests and cognitive schemes. Theory and interpretation are inseparable, although permanently on the verge of undermining and overcoming each other. To same the same thing differently: interpretation is the humble and practical reality of theory. Or, to return to Frank Zappa: theory is not dead, it just smells like interpretation.

\section{Indisciplinarity}

It is now time to explore a structural tension between the four dimensions of intellection, a.k.a. modalities of interpretation, described above. Accounting and modeling are often performed along intuitive lines, as it is the case when I look at a crowd and estimate there are about a hundred people in the room, or when I correlate a recurring computer crash with a 
certain ill-fated combination of operations. Accounting and modeling, however, can be subjected to highly disciplined procedures of observation and explanation, which we tend to identify with "the scientific method". These two dimensions are better-suited to pursue the disciplinary ideal which carried "theories" in their pre-historical age, along with a certain articulation between power and knowledge.

By contrast, storytelling and speculating can be perceived as the representatives of difference-sensitive theory, insofar as they tend to "resist" our best efforts to submit them to any form of well-disciplined method. In spite of analytical philosophy's imperialist attempts to formalize and normalize the (only) "proper way to think", storytelling and speculating remain closer to arts, crafts, virtuosities, "bricolages", based on intuitive skills rather than rigid and reproducible techniques. Their most significant steps forward-if it even makes sense to describe them within any form of "progressive" evolution, which remains highly debatable - tend to come from indisciplined gestures which challenge and upset the way one used to tell stories or speculate.

In order better to understand the dynamic tension between these two sets of modalities of interpretation (disciplined $v s$. indisciplined), we need to take a step aside, and reconsider the relation between disciplinarity, inter-disciplinarity and what some of us attempt to designate as "in-disciplinarity".

At the dawn of the $21^{\text {th }}$ century, intelligence has to be conceived along reconfigured lines. It is no longer enough to be an "expert" in a specific field. Cognitive competence increasingly requires the ability to draw transversal connections not only between different disciplines but also, more crucially, between different levels of perception of the same problems. It is no longer enough horizontally to mix points of view coming from different disciplines, as inter-disciplinary approaches have done for a number of decades. A more drastic reshuffling of the cards is necessary, in order vertically to integrate different strata of knowledge and perceptions.

Of course, sociologists should speak with economists, and literary critics should speak with historians, in order, for instance, to understand why a population may be led massively to vote for a xenophobic party. But this type of horizontal crossing of points of view leaves out the vertical articulation between the experts (sociologists, economists, literary critics, historians, etc.) and the decision-makers, the news-providers, the readers, the voters, the consumers - all agents and instances who not only react to the (inter-)disciplinary knowledge provided by the experts, but who also shape the public debates and determine the types of questions about which (inter-)disciplinary experts will have to share their views.

Such a vertical integration - to which we can refer with the term indisciplinarityresponds to a triple necessity. First, it is made urgent by the fact that each of us already is, and will increasingly be, called upon to be simultaneously an expert (in one field or another) and a decision-maker (be it merely in terms of a decision to vote for A rather than B) and a news-provider (be it merely in terms of our daily conversations with our friends) and a father and a son and a polluter and a consumer (among many other things). We are increasingly caught in schizophrenic contradictions between our interests as shoppers (who look for the lowest available price tag) and as wage-earners (who need good jobs to remain in our countries), between our desire to find fulfilment on the workplace and our need to detach ourselves from our professional self. Because the positions we defend as experts both are influenced by, and influence in return, these other parameters of our existence, an indisciplinary reflection about the vertical integration of our multileveled selves is the only alternative to a collective collapse into schizophrenia.

Indisciplinarity is also made urgent by the necessity actively to build the type of argumentative common ground modern democracies need in order to be more than a formal farce: an indisciplinary approach is required not so much to solve problems as to debate about 
which questions are of main importance and should be treated in priority-something which no expert, nor any mere crossing of expert views, can decide. This, again, can only be settled though the vertical integration of the many layers that compose our social forms of life.

Finally, an indisciplinary attitude is required to foster the type of intellectual dissensus and invention that prevent public debates from turning around in repetitive and delusional circles, within the structural circularity of the mediasphere. Here, indisciplinarity relays the function of echoing and voicing dissidence, around which Wlad Godzich defined differencesensitive theory.

Indisciplinarity may be a new name, but its practice is as old as philosophy and literary studies (Loty, 2005, 245). The arts in general, literature in particular, and "theory" in its short lifespan during the past decades, have traditionally played the role of an indisciplinary platform on which societal issues could be addressed in a way that could integrate rational analysis and affective resonance, ethical questions and political positioning, judgement and empathy. It is therefore no surprise if indisciplinarity feels at home in literary, artistic and cultural studies. It is worrying, however, to see the traditional territory of indiscipline - the Humanities - progressively lose their status, their place and their funding (Nussbaum, 2010, 163).

The question "What's left of theory in our supposedly post-theoretical age?" can therefore receive at least two answers: first, as we saw above, what's left is an inseparable and intimate articulation between theory and interpretation; second, what's left is an urge to pursue the type of vertical integration characteristic of indisciplinarity. These two answers can merge into one, when one realizes that interpretation is indisciplinary by nature: it tends to make sense of our world by framing our observation along the points of view defined by our practices (through the notion of relevance); it has to do so through a constant reinvention of its procedures, of its sensitivities, of its meanings, in a dynamic which forces it to by-pass and overflow any pre-defined disciplinary limitation. While the activity of reading can rest on the simple recognition of features pre-determined by the proper knowledge of a certain code, the activity of interpretation calls for the necessary questioning, suspending, supplementing, reinventing of the pre-existing codes. The subject is in position to interpret when $\mathrm{s} /$ he has to supply part of the code with its very act of deciphering (Citton, 2007, 363, 2010, $87 \& 2011$, 377).

While melting theory into indisciplinary (and indisciplined) interpretation, as I am suggesting here, may have its advantages, it faces a serious problem, which I will address in my concluding section: does interpretation still have a place in our current mediasphere dominated by speed (Rosa, 2010), liquefaction (Bauman, 2000, 228) and the collapse of any critical distance between the representation and the represented (Baudrillard, 1995, 164)? We may not have made any progress by re-qualifying our post-theoretical age as the age of indisciplinary interpretation if, in our current modes of communicating, interpretation "smells as funny" as theory.

\section{From Interpretive Authority to Exemplary Gestures}

Italian critic and theorist Daniele Giglioli has provided the most succinct and the sharpest characterization of the possible demise of interpretation at the beginning of our third millennium. In his article "Three Circles. Critique and Theory", he returns to the famous declaration attributed to Karl Rove, George W. Bush's spin doctor, who, responding to attacks against White House policies, derided those journalists and editorialists living "in what we call the reality-based community", naïve enough to "believe that solutions emerge from [their] judicious study of discernible reality":

"That's not the way the world really works anymore," he continued. "We're an empire now, and when we act, we create our own reality. And while you're studying 
that reality—judiciously, as you will—we'll act again, creating other new realities, which you can study too, and that's how things will sort out. We're history's actors... and you, all of you, will be left to just study what we do." (Suskind, 2004, 44)

Karl (Rove) had taken Karl (Marx)'s eleventh Thesis on Feuerbach one step further. It is not enough to call philosophers (i.e., theorists), who so far "have only interpreted the world in various ways", to now "change it": in the $21^{\text {st }}$ century, it belongs to spin doctors and PR agencies to "create it" - without feeling any urge to account for "reality" as it is, and without any sense of accountability for what will thus be created. This Baudrillardian twist, reclaimed from French theorists and academic types in order to become the official doctrine of Empire's central intelligence agency, could indeed be perceived as both the apex and the collapse of (difference-sensitive) theory. Disciplined, methodic, rational, "objective" accounting and modeling have been set aside, leaving an unlimited open field to manipulative storytelling (with the triumph of spin doctors) and delusional speculation (with the unbound madness of US narcissistic imperialism).

Within this broad historical context, Daniele Giglioli identifies three major crises simultaneously affecting three correlated circles. The first circle is centered on the crisis in the linguistic paradigm, whereby linguistics and semiology have been supplanted by cognitive sciences as the leader of the way we account for and model the social sciences. The third circle is reconfigured by the crisis in secularization, whereby modernity's critical stance against religion and "superstition" not only appears as a denial of the constant resurgence of the sacred in our social relations, but has ended up undermining any workable definition of "the subject". I will only dwell here on the second circle, which revolves around the end of the hermeneutical paradigm, which sheds a dramatic new light on the (im)possible future of theory as interpretation:

Interpretation has always configured itself as a practice to be applied to objects whose value was already guaranteed. First the sacred book, then the law and, only from the end of the $18^{\text {th }}$ century, the literary text [...] Only privileged texts (foundational, decisive, complex, difficult) have the right to be interpreted. In claris non fit interpretatio. That is why literary interpretation has managed to become, for a couple of centuries, a respected profession, strengthened by the allied authority of knowledge and power, culture and institutions, prestige and dignity, method and curriculum. (Giglioli, 2011, 23, translations mine)

Over the past decades, however, the process of commodification and of masscommunication has brought down this privileged status of (literary) interpretation:

"high-culture" texts have been progressively drowned into an ocean of symbolic production putting on the market objects which, one could say, do not desire to be interpreted. Mass communication, cultural industry, mainstream, labels don't matter: what matters is that a video clip, a commercial ad, a blockbuster movie are not to be interpreted with the same instruments as a movie by Antonioni. Worse: they don't call for interpretation. In front of such products - which are in overwhelming majority, which constitute the main process of acculturation of younger generations, which homogenize our global mediascape, which generate value, because they are sold worldwide and because they impose their models on our perceptions - the interpretive posture is bound to be a fallacy. There is nothing more ridiculous than a professor in communication laboriously analyzing a video clip to a teenager - who understands it much better than the professor, in a blink, while simultaneously sending an SMS and chatting on Facebook. Speed, superficiality, surfing, distracted attention (already noted by Benjamin about cinema), acceptance devoid of any anxiety about the abyss of simulation: such are the 
attitudes requested by this type of cultural products - in perfect opposition to the interpretive posture. (Giglioli, 2011, 24)

The demise of interpretation comes with a price to pay: the waning of the critical stance. By pushing us to find another (deeper) meaning hidden under the surface of the text, the interpretive attitude was a strong vector of potential criticism, leading interpreters and theorists often to side with dissidents. Daniele Giglioli continues (and ends) the story of the professionalization of the theorist sketched twenty years earlier by Wlad Godzich: "why in the world should governments and capital pay a salary to professional debunkers? What are these departments of Cultural Studies, where theory went to find shelter (sorry: to triumph), if not places of enshrinement for subversives?" (Giglioli, 211, 25).

Instead of lamenting over the demise of interpretive authority, which was the remnant of an old heavily hierarchical world we have few good reasons to regret, "critique and theory should venture into a territory already within our reach, but still in need to be claimed and appropriated":

Critique and theory should evolve from interpretation to exemplification, they should consider themselves not so much as thought or communication than as gestures, as performances, as events, as constitutive processes which provide themselves with their own rules along the way of their unfolding. [...] They should claim to those who listen: what matters is not what I say, nor the method I use to say it, but rather the very fact that I manage to speak through the techniques I use. Not: see what is in this text! But: see what can be done by reading, hearing and scrutinizing this text! [...] It is only by moving from enunciation to gesture, from symbol to example, from discourse to action, that theory and critique can still hope to have a future. (Giglioli, 2011,26)

This appeal to stage interpretation as an exemplary gesture, purported to be contagious, transductive, electrifying-rather than as an authoritative provider of hidden truthsremarkably converges with Wlad Godzich's call for a theory whose "practice consists in inventing gestures that are, at one and the same time, dedicated to the cry and a demand for an accounting from the System" (Godzich, 1994,31, italics mine). The agency proper to theoryas-interpretation is to be located in the inspiring and radiating power of the gesture: it rests on the force of exemplarity at least as much as on the force of truth (Hampton, 1990,305).

\section{Theoricolage}

I will conclude this reflection by suggesting a final shift which may help entice more future MA students to take courses in re-labeled (Literary) Theory. Modeling and speculation need to be humbled down from their theoretical pedestal in the same manner as interpretation needs to be humbled down from its authoritative hermeneutical altar. Theorists and interpreters should openly admit that - like all of us - they don't really know what they say, think or do. They try their best, but they don't know. And they know they don't know. And they are not afraid (although still duly ashamed) of saying it.

My students are wise to be repelled by theoretical claims insofar as most of these claims tended to be sickeningly arrogant. In order to neutralize such arrogance, which is probably inherent to any form of assertion resting on an effort to include a view from above, I suggest for "Theory" to re-label (and reconceive) itself as bricolage (a.k.a., do-it-yourself). In a famous excerpt of The Savage Mind, French anthropologist Claude Lévi-Strauss contrasted the techno-scientific approach illustrated by the engineer, the scientist or even the craftsman, with the "primitive", improvisational and "devious" approach illustrated by the "bricoleur":

The "bricoleur" is adept at performing a large number of diverse tasks; but, unlike the engineer, he does not subordinate each of them to the availability of raw materials and 
tools conceived and procured for the purpose of the project. His universe of instruments is closed and the rules of his game are always to make do with "whatever is at hand", that is to say with a set of tools and materials which is always finite and is also heterogeneous because what its contain bears no relation to the current project, or indeed to any particular project, but is the contingent result of all the occasions there have been to renew or enrich the stock or to maintain it with the remains of previous constructions or destructions. The set of the "bricoleur's" means cannot therefore be defined in terms of a project (which would presuppose besides, that, as in the case of the engineer, there were, at least in theory, as many sets of tools and materials or "instrumental sets", as there are different kinds of projects). It is to be defined only by its potential use or, putting this another way and in the language of the "bricoleur" himself, because the elements are collected or retained on the principle that "they may always come in handy". (LéviStrauss 1966, 20)

What people have practiced under the pompous term of "theory" has always been close to what Lévi-Strauss describes as bricolage: no matter how well-versed we are in the existing corpus of theoretical and methodological texts, we only operate with "a set of tools which is always finite" - and always insufficient to do justice to the complex realities facing us. This is why any interpretation needs to be indisciplinary: as we inherit them, the disciplines are always necessarily lacking, in constant need of supplementation, correction, sharpening and weeding. They fail us when we try to account for the nuances of the text, or when we try to model the peculiarities of the process we observe. They fail us because they were designed for purposes which never fully coincide with ours. Ultimately, they fail us because they do not emanate from the singularity of who we are and what our object is. Since all of us have to "perform a large number of diverse tasks", we constantly have to improvise new indisciplined tools and skills.

Our set of tools, materials and skills is thus fatally "heterogeneous". We have gathered them along the way, not from a superior and integrative position endowed with a view from above, but as wayfarers hunting and collecting opportunities as they crossed our wandering path. Our toolbox is "the contingent result of all the occasions there have been to renew or enrich the stock". When he states that "the set of the bricoleur's means cannot be defined in terms of a project", Lévi-Strauss contrasts the bricoleur with the engineer, in a comparison which sheds an interesting light on the difference between the pre-historical theories and difference-sensitive theory. Jean-François Lyotard famously defined the postmodern by the liquidation of modernity's conception of itself in terms of project (Lyotard, 1993. Since we are not too sure of what to project nor of what to expect, we better equip ourselves with whatever may "come in handy". While the disciplined technician tends to become hostage to the narrow set of specific tools he has devised for his pre-determined project, the indisciplined bricoleur, facing an undetermined future, attempts to maximize his polyvalence. His main question is identical to the one raised by Daniele Giglioli in order to justify the exemplary gesture of interpretation: not "how can we accomplish this project most efficiently?", but "what can be done by reading, hearing and scrutinizing this text?"

Beyond, beside or within the wide diversity of our intellectual activities, our various modalities of interpretation can participate in a common exemplarity if they conceive and stage themselves as gestures of bricolage. What interesting things can we do with what is at hand? Answering this question may be a less ambitious than providing a grand theory of politics, literature or history. But its very humility and practicality may help draw more students to our classrooms.

It would be deceptive, however, to see bricolage as an alternative to theory. The exemplary nature of the interpretive gesture results from the fact that it attempts to conciliate, rather than oppose, theory with bricolage - generating a hybrid we could baptize theoricolage. 
If the bricoleur's versatility results from his attempt "always to make do with 'whatever is at hand", his horizon is limited by the fact that "his universe of instruments is closed". And this is why we need interpretation to be the continuation of theory by other means, rather than its replacement or burial. The theoretical drive which expresses itself in the activity of speculation is more necessary than ever, if we are to expand our universe of instruments beyond its current limitation and closure.

As examples of such theoricolage, one could look at the current work developed by French theorist-poet-editor-activist Christophe Hanna. In an important collection of essays, he reconstructs literary theory as a sub-branch of ufology (Hanna 2010 and Hanna 2011a). In a brief article, he observes his students, as they tease policemen when demonstrating against governmental policies, and uses their provocative gestures to model what political interventions can look like under our regimes of surveillance and control (Hanna 2011b). In a "statistical novel", published under the pseudo of La Rédaction, he aggregates the responses collected from dozens of people who happen to have Berthier for their family name, to whom he asked a series of questions about a 1993 hostage situation which dramatically increased Nicolas Sarkozy's visibility as a young politician - the point being to count and describe how we, as media consumers, re-model historical events when we remember and re-tell media stories (Hanna 2012). Accounting, modeling, storytelling, speculating: our four dimensions of intellection are interwoven through the medium of books, forewords, articles, websites, but also art practices, installations, and even phonecalls... Christophe Hanna's multidimensional theoricolages are impressive and compelling for their invention and far-reaching stakes, while always remaining tongue-in-cheek.At this conclusive point, another tension emerges within our four dimensions of intellection. While accounting and storytelling can be located on the side "the given" (data), of which we try to make sense, the main function of modeling and speculating seems oriented towards the expansion of our toolboxes and horizon. We are bound to count and narrate the given with the imperfect and often blunt tools available as we walk along the path of life; by devising explanatory models and speculation, however, we can hope to sharpen, expand and enrich our set of instruments.

We need theoricolage to pursue the search for new tools (concepts, contraptions, devices and tricks) which animated theory in its pre-historical as well as in its historical agewhether to foster our power and knowledge, or to make ourselves more sensitive to the cries and promises of dissidence. We simultaneously need theoricolage humbly to stage its fragility, in its necessary but nevertheless ridiculous and often comical attempt to comprehend that which cannot be (fully) comprehended. The interpretive gesture can be truly exemplary only if it manages to disarm its unsustainable pretention to truth and authority (Citton 2011, 377).

Indiscipline will be all the more effective if it appeals to joyous and cheerful souls, rather than to subdued and obedient minds. The fact that theory smells "funny" may be, after all, excellent news - if only this sort of "fun" keeps us from taking ourselves too seriously.

\section{References}

AKRICH, M., CALlON, M., LATOUR, B., 2006. Sociologie de la traduction: Textes fondateurs. Paris: Ecole des Mines.

BAUDRILLARD, J., 1995. Simulacra and Simulation. Ann Arbor: University of Michigan Press, [Simulacres et simulations, Galillée, 1981].

BAUMAN, Z., 2000. Liquid Modernity. Cambridge: Polity Press. 
BLANCHOT, M., 1989. The Space of Literature. Lincoln: University of Nebraska Press, [trad. L'espace littéraire, Gallimard, 1988].

BRYANT, L. et al., 2011. The Speculative Turn: Continental Materialism and Realism. Melbourne: re-press.

BUTLER, J. et al., 2000. What's Left of Theory?, New York: Routledge.

CALLUS, I. et al., 2004. Post-Theory, Culture, Criticism, Amsterdam: Rodopi.

CITTON, Y., 2007. Lire, interpréter, actualiser. Pourquoi les études littéraires? Paris: Éditions Amsterdam.

CITTON, Y., 2010. L'Avenir des Humanités. Économie de la connaissance ou cultures de l'interprétation?, Paris : La Découverte.

CITTON, Y., 2011. Zazirocratie. Très curieuse introduction à la biopolitique et à la critique de la croissance. Paris: Éditions Amsterdam.

CUSSET, F., 2008. French Theory. How Foucault, Derrida, Deleuze, \& Co. Transformed the Intellectual Life of the United States. Minneapolis: University of Minnesota Press.

DESCOLA, P., 2005. Par delà nature et culture, Paris: Gallimard.

EAGLETON, T., 2003. After Theory, New York, Basic Books.

FISH, S., 1981. Is There a Text in the Class?Cambridge: Harvard UP.

GIGLIOLI, D., 2011. "Tre cerchi. Critica e teoria". Il verri, No. 45, Milano, February 2011, p. 17-31.

GODZICH, W., 1994. The Culture of Literacy, Cambridge: Harvard UP.

HAMTON, T., 1990. Writing from History. The Rhetoric of Exemplarity in Renaissance Literature. Ithaca: Cornell University Press.

HANNA, C., 2010. Nos dispositifs poétiques. Paris: Questions théoriques.

HANNA, C., 2011a, "Pourquoi théorisons-nous (encore) ?", introduction à Dominiq JeNVREY, Théorie du fictionnaire, Paris: Questions théoriques.

HANNA, C., 2011b, "Actions politiques/actions littéraires" in Collective, "Toi aussi, tu as des armes ». Poésie et politique, Paris: La Fabrique.

[HANNA, C., 2012, under the name] LA RÉDACTION, Les Berthier. Portraits statistiques, Paris: Questions théoriques.

INGOLD, T., 2007. Lines. A Brief History. London: Routledge.

INGOLD, T., 2011. Being Alive. Essays on Movement, Knowledge and Description. London: Routledge.

KNAPP, S. and Benn Michaels, W., 1982. “Against Theory”. Critical Inquiry, Vol. 8, No. 4, p. $723-742$.

LATOUR, B., 1991. We Have Never Been Modern. Cambridge: Harvard UP, [Nous n'avons jamais été modernes : essai d'anthologie symétrique, Ed. La Découverte, 1991]

LATOUR, B., 2012. An Inquiry into Modes of Existence. Cambridge: Harvard UP, [Enquête sur les modes d'existence : une anthropologie des Modernes, Ed. La Découverte, 2012].

LÉVI-STRAUSS, C. 1966. The Savage Mind, Chicago UP; [La pensée sauvage, Plon, 1969]

LOTY, L. 2005. "Pour l'indisciplinarité". Studies on Voltaire and the Eighteenth Century, Oxford, Voltaire Foundation, 2005:04, p. 245-259.

LYOTARD, J.F. 1993. The Postmodern Explained. Correspondence 1982-1985, Minneapolis: University of Minnesota Press, 1993 [Le Postmoderne expliqué aux enfants, Paris : Galilée, 1988]

MCMILLAN, M., 1999. Post-Theory. Edinburgh: Edinburgh UP.

MEILlASSOUX, Q., 2009. After Finitude. An Essay on the Necessity of Contingency. New York: Continuum, [Après la finitude : essais sur la nécessité de la contingence, Seuil, 2006] 
NUSSBAUM, M., 2010. Not For Profit: Why Democracy Needs the Humanities. Princeton UP.

RICOEUR, P., 1990. Time and Narrative, vol 1. University of Chicago Press, [Temps et récit : le temps raconté, Seuil, 1985].

ROSA, H., 2010. Alienation and Acceleration. Towards a Critical Theory of Late-Modern Temporality. Copenhagen: Aarhus University Press.

SHUSTERMAN, R., 1984. The Object of Literary Criticism. Amsterdam: Rodopi.

SUSKIND, R., 2004. "Faith, Certainty and the Presidency of George W. Bush", New York Times Magazine, October 17, 2004.

ZUBLENA, P., 2011. "Dopo la teoria". Il verri, No. 45, Milano, February 2011, p. 5-16. 